\title{
Transcending Convention and Space: Strategies for Fostering Active Learning in Large Post-Secondary Classes
}

\author{
Andrea Quinlan ${ }^{1} \&$ Curtis A. Fogel ${ }^{2}$ \\ ${ }^{1}$ Department of Science and Technology Studies, Cornell University, New York, USA \\ ${ }^{2}$ Criminology, Lakehead University Orillia, Ontario, Canada \\ Correspondence: Andrea Quinlan, Department of Science and Technology Studies, Cornell University, Ithaca, \\ NY, 14583, USA. E-mail: agq2@cornell.edu
}

Received: September 14, 2014

Accepted: October 4, $2014 \quad$ Online Published: November 13, 2014

doi:10.5539/hes.v4n6p43

URL: http://dx.doi.org/10.5539/hes.v4n6p43

\begin{abstract}
In 1970, education theorist Paulo Freire (1970) sharply critiqued dominant pedagogy—or what he called the banking model of education - for stripping students of their agency. In the banking model, he wrote, instructors are empowered as narrating subjects as students who become alienated as passive listening objects. In the decades since, research has repeatedly shown that a banking model of education is ineffective and inefficient. Despite this, there is an increasing trend towards large, lecture-based learning in post-secondary classrooms, fuelled largely by the turn to a neoliberal, corporatized model for higher education. Active learning pedagogy moves away from the banking model of education, toward a model that positions the student as an active participant in his or her own learning and development. While active learning has been shown to be more effective, large class sizes, classroom structures, teaching loads, and diminishing teaching resources can make it difficult for instructors to integrate active learning into large post-secondary lecture-halls. This paper explores the challenge of inspiring active learning in large classes and proposes a number of strategies for integrating active learning in large university lecture halls.
\end{abstract}

Keywords: active learning, higher education, pedagogy, large class sizes

\section{Introduction}

It has long been known that learning typically requires more than listening and instead demands activation and engagement of the mind. Despite this, university classroom sizes and structures tend to promote lecture-based teaching and learning. Describing this trend, McKeachie (2006) indicates that in a typical post-secondary classroom setting, students are often only passively involved in their learning. McKeachie's observations are not new. Decades earlier, Paulo Freire (1970) penned a sharp critique of what he called the banking model of education, which he argued transforms students into "passively listening objects", while simultaneously transforming the instructor into a "narrating subject" banking information into the students' minds (p. 45). Freire (1970, p. 45) argued,

"Education is suffering from narration sickness. The teacher talks about reality as if it weremotionless...or he expounds on a topic completely alien to the existential experience of the students. His task is to "fill" the students with the contents of his narration...Words are emptied of their concreteness and become a hollow, alienated, and alienating verbosity...Education thus becomes an act of depositing, in which the students are the depositories and the teacher is the depositor. Instead of communicating, the teacher issues communiqués and makes deposits which the students patiently receive, memorize, and repeat."

According to Freire, the consequence of this pedagogical model is a population of disengaged and alienated students and citizens.

Active learning provides a contrast to banking models of education. Active learning pedagogy moves away from a strict lecture-based teaching, toward a pedagogy that positions students as active participants in a collective learning endeavour (Hammer \& Giordano, 2012). Although active learning pedagogies may be relatively common in small advanced level classes where student involvement is often an expectation, it is increasingly difficult to achieve in lower level university courses, particularly those that have hundreds of students in one lecture hall. 
With the recent turn to a neoliberalized and corporatized model for higher education in Canada and other countries, budgets for undergraduate programs are being drastically cut and accordingly, lecture sizes are growing exponentially while teaching resources are dwindling. In this climate, large lecture halls with hundreds of students have become commonplace. The physical structure of these rooms reflect Freire's banking model and inspire passivity and disconnectedness amongst the students. The sheer size of the room, the organization of the chairs and lecture stand, and the number of students, do not facilitate active engagement with the course material, the professor, or other students. The lack of teaching resources often precludes individualized instruction and long written assignments, forcing instructors to use more common means of mass evaluation, such as multiple choice and true/false exams. With these increasing pressures to conform to lecture-based teaching, how can post-secondary instructors engage students in large university classes? In this paper, we consider the question: how might post-secondary instructors transcend the barriers imposed by space and convention and activate students' engagement and learning?

According to Hawtrey (2007), "learning occurs whenever the student is roused from the role of passive listener to that of active respondent" (p. 144).This form of learning is the foundation of active learning. It involves inspiring students to think, talk, move, and invest in their own learning. Hammer and Giordano (2012) describe active learning as "a student-centered approach to teaching and learning, in which teachers ignite student thought, reflection, application, and curiosity. Students are not merely passive listeners, but instead active problem-solvers who begin to see themselves and their peers as sources of knowledge" (p. 100). The active learning model gained prominence in North America through a report to the Association for the Study of Higher Education (Bonwell \& Eison, 1991) that identified the limitations of conventional teaching approaches that focus on students' listening and promoted an approach to teaching that would activate their minds. Bonwell and Eison's (1991) report builds upon the early work in the 1980s on active learning. Most predominantly, they draw on the work of Chickering and Gamson $(1987$, p. 2) who write:

"Learning is not a spectator sport. Students do not learn much just sitting in classes listening to teachers, memorizing pre-packaged assignments, and spitting out answers. They must talk about what they are learning, write about it, relate it to past experiences, and apply it to their daily lives. They must make what they learn part of themselves."

Active learning thus occurs through thinking, processing, examining, reflecting, synthesizing, experiencing, rather than merely listening.

While the pioneering work on active learning relied on intuition and antidotal evidence of effective teaching and learning, in the decades since there have been systematic empirical studies that have reported the various drawbacks of listening-based, lecture-based pedagogy in comparison to active learning approaches. The drawbacks that have been noted include, but are not limited to, a low level of comprehension, poor long-term memory retention, low average grades, high student enrolment attrition rates, low student satisfaction, and feelings of alienation from the education process (Bain, 2004; Halpern \& Hackel, 2003; Owen-Smith, 2004, 2007; Prince, 2004; Svinikie \& McKeachie, 2011). We argue that the problems extend further. The lecture-based model promotes passive, disengaged and disconnected students, and therefore passive citizens who are disengaged and disconnected from each other. The lecture-based model of education transforms students into passive consumers of information. In contrast, active learning has the potential to inspire students to become more engaged and empowered citizens. It is this vision of learning that we mean to explore.

\section{Strategies for Fostering Active Learning in Large Classes}

Strategies for fostering active learning have traditionally been broadly conceived, from in person or online classroom discussions to small group discussions, student debates, working with primary data in assignments and learning activities, playing learning games in the classroom, having students conduct primary research, and various forms of community-based learning (Renkl et al., 2002; McKeachie \& Svinicki, 2006; Light \& Cox, 2001). Evidence suggests that all of these instructional tools can improve student learning outcomes and overall student satisfaction in their learning experience. However, in the context of large lecture halls, many of these strategies are difficult to execute, if not impossible.

One of the biggest challenges for instructors teaching large classes is to hold students' attention. Research suggests that an average student can only grasp lecture material for a limited period of time before their concentration wanes (Carbone, 1998). Typical class times run from one to three hours, during which many students struggle to maintain concentration. These difficulties are made worse in large classrooms where students' attention can bemore easily drawn in different directions. Another major difficulty of teaching large class sizes is minimizing disruptive student behaviours. When students' attention to the lecture material begins to 
wane, private conversations and social media use often increase. Under the weight of these distractions, it becomes difficult for the instructor to bring students' attention and interest back to the course material. Some of these common challenges in large lecture halls can be tackled with teaching strategies that inspire active learning.If students are given the opportunity to explore course material in ways that inspire, activate, and engage them, they will become active contributors to a classroom climate that more conducive to learning.

In this paper, we draw on our own experiences of teaching large Sociology and Criminology courses to examine active learning strategies that we have found useful inlarge classrooms. By large, we refer to class sizes exceeding 100 students in a lecture hall. The methodological approach used in this paper is autoethnographic, drawing on experiences in 16 large classes taught by the authors over the past four years. Autoethnography, in a basic sense, involves reflection and writing that explores the lived experiences of the researcher, or in this study, researchers (Heewon, 2008). This paper presents our reflections on strategies that have worked for us in engaging students to be active participants in the learning process.

Most of these strategies involve classroom activities or exercises that are intended to inspire engagement, debate, and discussion. We do not see these strategiesas a definitive or exhaustive list of all possible strategies. Nor do we presume that these strategies will be equally effective in all classrooms-their effectiveness is dependent on many things, including the dynamics of a particular class, the discipline under instruction, an individual instructor, a classroom space, and available resources, among other things. We propose these strategies as a call for more dialogue on how post-secondary instructors can inspire active learning in increasingly large class sizes. The five strategies we focus on here include: i) establishing a commitment to the learning process, ii) active evaluation mechanisms, iii) reality disruptions, iv) imagined solutions, and v) arts-based pedagogy.

\subsection{Establishing Commitment}

Giving students the opportunity to reflect on their learning process and develop strategies for its improvement can help to establish and strengthen their commitment to learning. Instead of imposing strict rules and structure on students' learning (e.g., classroom conduct, student participation, etc.), instructors can offer students the chance to think critically about their learning and encourage them to devise their own solutions to challenges that they may face along the way. Through this kind of active reflection, learning is no longer a passive phenomenon imposed onto students by a professor. Instead, learning is explicitly reconfigured as an active process that hinges on students' continued engagement and commitment. Developing this kind of commitment in large classes can help to establish a learning environment that is conducive to active learning pedagogies.

In a large classroom, student reflection on learning processes can be done in one of two ways. Students can be asked individually to think about on their own learning process. At the beginning of a course, an instructor might give the students a series of survey questions that prompt their thinking about how they learn and ask them to devise strategies for their success in the course. While this may help to inspire some students to think concretely about their learning, it may not for others. More importantly, however, this strategy fails to address the complex nature of learning in large groups of people in big lecture halls. Embedded within the individual survey strategy is an understanding of learning as an individual activity. In a large lecture hall, learning is, however, a collective affair. Therefore, student strategies for learning in a large lecture hall must be derived not only individually, but also collectively. Giving students a chance to dialogue with one another about the challenges of learning in large lecture halls provides a forum for exchange and collective consideration of a collective set of problems.

We have often begun our classes by asking students questions that inspire their collective reflection on learning: What are some things that happen in lectures that make it difficult for you to learn? Common responses include: students talking during lecture, other students using Facebook and cellphones during lecture, and loud eating. From these questions, students develop a list of disruptive activities in the classroom, which we write on the front board for all students to see. By writing the list on the board, students see what actions their classmates find disruptive. This can encourage students to think of themselves not as individual passive recipients of knowledge, but as a group of people learning in a shared space. Once the list is complete, we ask students to develop some classroom rules that will address the problems they have identified with learning in a large lecture hall and make the shared space a more conducive learning environment. The rules are collectively derived with input from as many students as possible. Once agreed upon, these rules are posted on the course website and are referred to throughout the course. By creating shared rules, students are often more invested in maintaining a classroom space that is conducive to collective learning throughout the course.

\subsection{Reality Disruptions}

There are several strategies that we use to disrupt our own lecture-based narration and encourage the students to more actively engage with the course material. One strategy centers on disrupting realities, an approach that 
involves replacing actual realities with imagined ones. This strategy breaks the pattern of fact-based narration in the lecture hall with an imagined, fictitious reality that highlights social issues that the instructor wants to introduce and problematize. It forces students to think, separate fact from fiction, and reconsider the status quo.

We have used this approach by presenting students with alternative, often futuristic, events and happenings. For example, a mock newspaper article can be presented to students reporting on events that have never happened or have not yet happened. A class on sexism in sport might open with an article detailing the first overall selection of a female basketball player in the National Basketball Association (NBA) draft. Any students with a passing interest in sport will quickly recognize that no female basketball player has ever played in the NBA, let alone been drafted with the number one pick. Or, a class on gender and inequality might open with an article detailing a new funding initiative of the federal government that covers all post-secondary education costs for single mothers. Presenting students with a fictitious reality often sparks an engaged discussion of "what if", which encourages students to think about the world around them from a new vantage point.

To open a class on the criminalization of controlled substances, we have used a mock docudrama film titled If... Drugs Were Legal (2005). The mock documentary depicts a British society where most previously illicit drugs have been decriminalized and legalized. The film shows real life experts on drug crimes, addictions, and drug policy, who discuss the implications of drug legalization, but the reality that the film is set against is an imagined one: England has not decriminalized or legalized the various drugs discussed in the film. Students must then grapple with sorting out what is real versus that which is imagined. It also sparks ideas of what might be possible and can allow for critical reflection on the ways that things currently are. BBC has made several versions of these mock docudrama films exploring many social issues including: pension plans, natural resource importation, social stratification, patriarchy, obesity, violence, and cloning.

\subsection{Imagined Solutions}

The prevailing assumption of university education — dictated by convention and tradition —is that expertise in the university lecture hall lies at the front of the room. While the professor professes, the students passively and quietly retain what is being professed. Activating students involves disrupting this uneven distribution of expertise by giving students the opportunity to use their own experiences and knowledge as the basis of exploring difficult course material. This can be done through a technique that we call imagined solutions.

We have used imagined solutions in a variety of Sociology courses. In a Sociology of Work class we use this technique during discussions of precarious (under) employment for recent university graduates, a topic that is of particular personal relevance to many of the students. We begin the class by dividing the students into large "policy think tanks" (10-12 students). Each group is given a relevant institution, for which they are responsible for developing policy (eg. federal government, provincial government, universities, high schools, etc.). We ask the groups to develop new policies that their institution will implement, which will address underemployment of university graduates. Through their discussion and debate on potential policies, students come to see the issue as being inherently complex. When the groups agree on their proposed policies, they write them on the front board. We ask the class to reflect on all of the proposed policies and the potential relationships between them. Through this activity, the students' own understandings and solutions to underemployment are used to spark deeper theoretical discussions of the interrelationships between work, the economy, and social policy.

Asking students to use their own expertise to begin exploring a course concept not only connects the course material to what they already know, but can also help to inspire a greater investment in learning. The diversity of experiences in large classes enhances any discussion that uses students' experiences as the basis for exploration.

\subsection{Arts-Based Pedagogy}

Integrating the popular arts, such as visual and theatre-based activities, into large lecture-based classes can challenge students to engage with the lecture material in new and different ways. In social science courses, and perhaps in other disciplines as well, the arts can encourage students to think more abstractly, creatively, and cooperatively about difficult concepts featured in the lecture. Scholars in the popular arts have long argued that the arts need not be reserved for trained experts. Instead, the arts can be used to facilitate conversation about difficult and challenging social issues. In large lecture halls where dialogue is sometimes challenging to initiate, the arts can be a useful tool for sparking student engagement and discussion.

We often begin our introductory Sociology of Family lectures by asking students to draw a family. We place no restrictions on the type of family that they are to draw. In fact, we ask them specifically to draw the first type of family that comes to mind. The students are then divided into large groups of 10-12 (can be larger or smaller, depending on the number in the class). They lay out all of their drawings and begin to discuss the commonalities 
and differences between them. We tell students to focus on the content of the drawings and ask them to consider the types of families that are represented in their collection of drawings. Students then categorize their drawings into family types, which they write on the front board alongside their drawings. Once all the groups have arranged their categorized drawings on the front board, the class is asked to examine the range of family types that appear, and to reflect on the dominant patterns that they see. Students observe the large number of drawings that feature nuclear heteronormative families, and from their own observations emerges a theoretical understanding of dominant heteronormative constructions of the family.

We have similarly employed theatre-based activities to spark class discussion about difficult theoretical concepts. In particular, we have drawn on theatre games Augusto Boal (2002) developed as part of what he termed Theatre of the Oppressed; a set of theatrical techniques for promoting collective dialogue about political issues and social change. For example, we have used Boal's chair sculpture as a way of introducing Marxist and functionalist theoretical perspectives in introductory Sociology. The chair sculpture begins by the instructor placing a chair at the front of the room. Individual students then volunteer to come to the front and place a chair somewhere in relation to the others. Through this process, the students collectively build a large-scale sculpture of chairs. Once all students who want to participate have contributed a chair to the sculpture, it becomes the focus of discussion. We ask the students: What do you see in this sculpture? What is going on between these chairs? Which chair is in power? Which chair is the least powerful, subordinate, or marginalized? How do you know? As students consider these questions and debate their answers, what often emerges is a theoretical understanding of power as being relational. The chairs serve as a metaphorical vision of a society that allow students to visualize relations of power, often one of the most difficult concepts for introductory Sociology students.

We then begin to apply some of the theoretical concepts to the discussion, and ask students: Which chairs in this sculpture might Marx see as the bourgeoisie? Or the proletariat? Why? How might Durkheim understand the relationships between these chairs? Does this group have organic or mechanical solidarity? Why? How do you know? Because the sculpture is the students' own creation, and they are being asked to engage their imaginations and creativity to interpret it, the students are often eager to participate in what becomes a deeply theoretical discussion of social structure, social power, and contrasting branches of sociological thought.

Drawings and chair sculptures are arts-based pedagogical techniques that are particularly effective in large classrooms. They require few resources and challenge students to think creatively and collectively about concepts in the lecture. These techniques are effective because of - not in despite of - the large number of students. It is through the contributions of many students that the class can begin to see social patterns and build collective understandings of challenging ideas and concepts.

\section{Concluding Thoughts}

In their report to the Association for the Study of Higher Education, Bonwell and Eison (1991) identify the largest barrier to active learning not as class size or design, but simply the fear of the professor. They suggest that professors fear that active learning techniques will not work; that students will refuse to participate, control will be lost in the classroom, and students will criticize the unorthodox practices of teaching. While this may be in part a reason for why active learning is not routinely used in university classrooms, it is not a satisfactory explanation. Increasingly large class sizes, teaching loads, and diminishing teaching resources can make it difficult for instructors to take on new and challenging teaching techniques. However, as we have proposed in this paper, large class sizes need not preclude active learning strategies. This paper has provided a few of the many possible strategies for integrating active learning into large post-secondary classes that can transcend convention and space. There are certainly many other strategies yet to be explored. As large lecture-based university courses increase in both size and number, it is imperative that instructors consider the implications for students learning and devise potential solutions to the problems that they raise.

\section{References}

Boal, A. (2002). Games for actors and non-actors (2nd ed.). New York: Routledge.

Bonwell, C., \& Eison, J. (1991). Active learning: Creating excitement in the classroom AEHE-ERIC higher education report, 1 .

Carbone, E. (1998). Teaching Large Classes: Tools and Strategies. Sage: Thousand Oaks, CA. http://dx.doi.org/10.4135/9781483328270

Chang, H. (2008). Ethnography as method. Walnut Creek, CA: Left Coast Press.

Chickering, A. W., \& Gamson, Z. F. (1987). Seven principles for good practice. American Association Higher Education Bulletin, 39, 3-7. 
Freire, P. (1970). Pedagogy of the oppressed. New York: Herder and Herder.

Hammer, E. Y., \& Giordano, P. J. (2012) Active learning. In W. Buskist, \& V. Benassi (Eds.), Effective college and university teaching: Strategies and tactics for the new professoriate (pp. 99-106). London: Sage.

Hawtrey, K. (2007). Using Experiential Learning Techniques. Journal of Economic Education, 38(2), 143-152. http://dx.doi.org/10.3200/JECE.38.2.143-152

Light, G., \& Cox, R. (2001). Learning and Teaching in Higher Education. Thousand Oaks, CA: Paul Chapman.

McKeachie, W. J., \& Svinicki, M. (2006). Teaching tips: Strategies, research, and theory for college and university teachers. Belmont, CA. Wadsworth.

Michael, J. (2006). Where's the evidence that active learning works? Advances in Physiology Education, 30(4), 159-167. http://dx.doi.org/10.1152/advan.00053.2006

Prince, M. (2004). Does active learning work? A review of the research. Journal of engineering Education, 93(3), 223-231. http://dx.doi.org/10.1002/j.2168-9830.2004.tb00809.x

Renkl, A., Atkinson, R. K., Maier, U. H., \& Staley, R. (2002). From example study to problem solving: Smooth transitions help learning. Journal of Experimental Education, 70 (4), 293-315. http://dx.doi.org/10.1080/00220970209599510

\section{Copyrights}

Copyright for this article is retained by the author(s), with first publication rights granted to the journal.

This is an open-access article distributed under the terms and conditions of the Creative Commons Attribution license (http://creativecommons.org/licenses/by/3.0/). 